\title{
ALGUMAS CONSIDERAÇÕES SOBRE AS IDEIAS PRÉVIAS DOS ALUNOS EM RELAÇÃO À TEMÁTICA ARQUEOLÓGICA E INDÍGENA: UM ESTUDO DE CASO EM LONDRINA-PR
}

\section{A U T O R A}

Leilane Patricia de Lima

leilaneplima@gmail.com
Doutoranda em Arqueologia no Museu de Arqueologia e Etnologia da Universidade de São Paulo, sob orientação do professor Dr. Pedro Paulo Abreu Funari. Bolsista CAPES.

\section{R E S U M O}

\section{A B S T R A C T}

As reflexões aqui apresentadas são frutos de uma experiência educativa desenvolvida com alunos do quinto ano do ensino fundamental em uma escola municipal de Londrina/PR. A formação deste município deu-se a partir de um projeto de colonização estrangeira, articulado pela Companhia de Terras Norte do Paraná, que ainda hoje gera exclusão e/ou negação da presença indígena. Assim, como elaborar, neste contexto, uma proposta educativa de sensibilização sobre esta presença, uma vez que a geração contemplada é descendente, direta ou indiretamente, dos colonizadores, exaltados como "pioneiros"? A partir disso, relata-se o primeiro passo do caminho metodológico percorrido: a investigação e a análise das ideias prévias dos alunos em relação à temática arqueológica e indígena.

\section{Palavras chave: Arqueologia Pública, Educação, Ideias Prévias.}

The ideas presented here are the result of an educational experience developed with fifth graders of elementary school in a public school in Londrina / PR. The birth of this city was the result of a project from foreign colonization, articulated by Companhia de Terras Norte do Paraná, which still generates exclusion and/or denial of indigenous presence. So how to make in this context, an educational proposal on this presence, since the generation is descending, directly or indirectly, of the colonizers, exalted as "pioneers"? From this, we report the first step of the methodological approach: research and analysis of previous ideas of students in respect to archaeological and indigenous theme.

Keywords: Public Archaeology, Education, Previous Ideas.

A Arqueologia Pública é uma área que está em desenvolvimento e aperfeiçoamento sobre suas ações. Muitas são as publicações, nacionais e internacionais, que discutem as atividades públicas da Arqueologia. No Brasil, estes debates têm alcançado novos caminhos e perspectivas e isto se deve, especialmente, à crescente inserção da Arqueologia no campo da ciência aplicada $^{1}$ (FUNARI; ROBRAHN-GONZÁLEZ, 2008: 3).

Apesar de o termo "Arqueologia Pública" ser de uso recente no país, ciência aplicada implica a percepção dos outros sujeitos do universo patrimonial e o reconhecimento do uso do passado como um caminho para o fortalecimento de comunidades com as quais lidamos durante nossas pesquisas (SILVEIRA; BEZERRA, 2007). arqueológico da sociedade realizados, já na década de 1960, por Paulo Duarte, Castro Faria e Loureiro Fernandes, que atuaram em favor da federalização da proteção do patrimônio arqueológico e da divulgação do conhecimento produzido (CARNEIRO, 2009:105). 
Na década de 1980, as exigências legais de proteção do patrimônio arqueológico brasileiro, estabelecidas de maneira mais incisiva a partir da legislação vinculada à Política Nacional de Meio Ambiente (CONAMA 01/86, Portaria SPHAN 007/88 e Portarias IPHAN 230/02 e 28/03), resultaram em uma retomada de preocupações preservacionistas e de divulgação do conhecimento científico (CARNEIRO, 2009: 105).

Desde então, há uma multiplicação de projetos e de publicações no país que apresentam discussões sobre os aspectos públicos da Arqueologia e que confirmam um momento favorável para novos debates. Estas discussões apontam que ainda não há um consenso sobre a Arqueologia Pública, pois quando se alcança a questão da aproximação com a sociedade, especialmente via ações educacionais, não há apenas um campo de atuação ou um plano de ação pré-estabelecido.

Ainda, é importante esclarecer que se convencionou no Brasil tratar as ações educativas de Arqueologia como ações de Educação Patrimonial. No entanto, entende-se aqui a Arqueologia Pública e a Educação Patrimonial como campos de conhecimentos distintos, que apresentam suas interconexões no país via legislação, especialmente depois da implantação da portaria 230/02 (CARNEIRO, 2009: 10).

A meu ver, a Arqueologia Pública é uma área de pesquisa dedicada a pensar tanto as relações da Arqueologia com os diferentes sujeitos do universo patrimonial quanto a dimensão social e pública do conhecimento arqueológico. $\mathrm{E}$, independentemente da denominação "Pública", esta é uma tarefa que pertence à Arqueologia como um todo, uma vez que esta ciência tem como objeto de estudo o patrimônio arqueológico, gerenciado como bem da União, cujo conhecimento produzido é de interesse comum do povo brasileiro.

De outro lado, a Educação Patrimonial foi instituída como uma metodologia, surgida no contexto de museus, para favorecer as relações entre o público escolar e o patrimônio cultural. Entretanto, nos últimos vinte e cinco anos, a Educação Patrimonial consagrou-se no Brasil não como metodologia, mas como campo de trabalho, reflexão e ação (CHAGAS, 2004: 144), que funciona independentemente da Arqueologia e que recebe contribuiç̧̃̃es de áreas diversas que lidam com o patrimônio cultural.

Dito isto, o presente artigo não discute a Educação Patrimonial, mas como a Arqueologia e o conhecimento científico por ela produzido podem ser importantes instrumentos para promover uma educação mais inclusiva e crítica no ambiente formal de ensino, conforme o estudo de caso apresentado a seguir.

\section{A formação histórica de Londrina}

O município de Londrina localiza-se no chamado Norte Novo do Paraná, cuja ocupação definitiva iniciou-se em 1925. A partir desse momento, a situação dos indígenas que por ali viviam (Kaigang, Guarani e Xetá) tornou-se cada vez mais preocupante, até ficarem nas reservas (MOTA, 2005: 69). Nas palavras desse autor: 
2 O plano inicial desta Companhia de Colonização era vender as terras do norte do Paraná aos curdos do Iraque para a produção de algodão, proposta advinda de uma visita de economistas ingleses em 1924. No entanto, uma forte campanha contrária a essa imigração foi desencadeada pela imprensa curitibana e carioca. Com o fracasso da proposta inglesa, paulistas, mineiros, nordestinos (da Bahia de Pernambuco etc.) e outros estrangeiros, tais como japoneses, talianos, alemães, espanhóis e poloneses, foram os maiores beneficiados com a aquisição das terras no norte paranaense (WACHOWICZ, 2001).
3 Atualmente, a região norte do Paraná conta com cinco reservas: Laranjinha e Pinhalzinho, habitadas por grupos indígenas Guarani; Apucaraninha e Barão de Antonina, por Kaingang; e São Jerônimo da Serra, onde vivem Guarani, Kaingang e Xetá. Ressalta-se que a reserva do Apucaraninha, que conta com o maior número de Kaingang no norte do Paraná, está sob jurisdição da Fundação Nacional do Índio (FUNAI), mas com administração regional de Londrina.

4 Sobre o assunto, consultar (NOELLI, 1999-2000); (RIBEIRO, 2000); (PARELLADA, 2005), entre outros.

5 Informação concedida durante a palestra "Missões Jesuíticas do Guairá - 1610-1631", ocorrida no dia 03/08/2011, no município de Cambé/PR. companhias colonizadoras. Estas companhias promoveram a ocupação da região em um ritmo acelerado [...]; em menos de trinta anos tudo estava desmatado e ocupado com vilas, cidades e grandes plantações de café (2005: 69).

Na região de Londrina, a colonização das terras ficou sob a tutela da Companhia de Terras Norte do Paraná (CTNP), subsidiária da firma inglesa Paraná Plantations, que, para chamar a atenção dos compradores², passou a revender as terras concedidas pelo estado como pequenas e médias propriedades. Também para atraí-los, a CTNP investiu no planejamento urbanístico da cidade e nas inúmeras propagandas veiculadas na época. O discurso mais comum era o de uma terra vazia, desabitada ou devoluta, sinônimo de futuro sucesso e realização (LIMA; ZARPELÃO, 2008: 207).

A ideia de "vazio demográfico" foi reforçada pela produção acadêmica entre as décadas de 1930 e 1960, pois o norte do estado foi alvo de visitas, excursões e passeios científicos. Os relatórios dessas visitas foram publicados por geógrafos, sociólogos e historiadores que reforçaram a questão de terras vazias e desabitadas, conforme aponta Mota (2009: 27).

Londrina, então, surge no ano de 1934, enquadrada neste cenário de "vazio demográfico" e de desenvolvimento por conta do café. A elite da cidade amparou-se nas ideias de progresso e Eldorado Cafeeiro, dando a sensação de grande êxito no futuro para aqueles que se aventurassem por aquelas terras. Tais ideias ensejaram a crença na fertilidade da terra, no enriquecimento público e privado, no fácil acesso às propriedades agrícolas e na riqueza possibilitada pela agricultura (LIMA; ZARPELÃO, 2008: 213).

No que diz respeito à presença indígena, estudos históricos apontam que o projeto colonizador da região foi violento e contou com a resistência dos índios que, de igual modo, revelava-se hostil. Segundo Ramos e Alves (2008: 183), a CTNP confirmou esta presença e classificou a retirada e o deslocamento destes grupos para reservas ${ }^{3}$ como "limpeza de área". Mas poucas são as fontes que relatam as lutas entre os "pioneiros" e os indígenas da região. Nas palavras dos autores,

A omissão da presença indígena na região, bem como a omissão de seus conflitos, quer pela propaganda da CTNP, quer pela literatura da época, pretendia criar a aparência de um lugar pacífico, de uma "Terra da Promissão", o paraíso prometido da fertilidade [...] (RAMOS; ALVES, 2008: 184).

A Arqueologia também contribui para a afirmação desta presença, pois as pesquisas indicam que o Paraná tem sido ocupado por diferentes populações humanas há mais de 12.000 anos$^{4}$. Pelos estudos arqueológicos foi possível evidenciar a presença dos caçadores-coletores (as chamadas Tradição Humaitá e Umbu), dos pescadores-coletores no litoral e das populações indígenas históricas (Guarani, Kaingang, Xokleng e Xetá) (MOTA, 2005: 113-117).

Na região metropolitana de Londrina, em específico, recentemente foi identificada a missão jesuítica San Joseph, que funcionou entre 1621-1625, pela arqueóloga Cláudia Inês Parellada, do Museu Paranaense ${ }^{5}$. 


\section{Londrina e os esforços educativos em prol do Patrimônio Cultural}

Esta breve discussão sobre a ocupação histórica de Londrina pode ser relacionada com os esforços educativos em prol da temática de seu patrimônio cultural. Desde 2005, a partir de ações promovidas pela Secretaria Municipal da Cultura, é desenvolvido o projeto "Educação Patrimonial". Arquitetos, urbanistas, historiadores, profissionais de turismo etc., ofereceram cursos de capacitação para professores da rede pública, passeios monitorados e produziram materiais didáticos que foram distribuídos gratuitamente para as escolas.

No ano de 2007, este projeto estendeu sua atuação para o público escolar e começou a desenvolver oficinas nas escolas da rede pública, com o objetivo de promover reflexões sobre o patrimônio cultural da cidade (MAGALHÃES et al., 2009: 66).

Dentre as atividades oferecidas aos alunos, é proposta uma reflexão sobre o conceito de herói, como um elemento importante para a constituição identitária de um grupo. E, ao tratar da ocupação da região, o papel do pioneiro ganha destaque como o "herói" que, juntamente com a CTNP, promoveu o sucesso da ocupação (MAGALHÃES et al., 2009: 72). Nessas ações propostas, a presença indígena não foi tratada.

Além deste fato, tive a oportunidade de colaborar em inúmeras atividades no Museu Histórico da cidade. Nas monitorias, não raras vezes ao questionar os visitantes (alunos do ensino fundamental, em sua maioria) sobre os primeiros habitantes da região, as respostas foram: "os ingleses", "os europeus", "os pioneiros". Poucos arriscaram "os indígenas" e outros preferiram o silêncio.

Diante de tal cenário, a Arqueologia tratada no contexto escolar pode servir como um importante instrumento para uma educação mais inclusiva e preparada para lidar com a temática indígena, contribuindo, assim, para a valorização da diversidade cultural e para a preservação do patrimônio arqueológico indígena local e regional.

\section{O primeiro passo da ação arqueológica educativa: a investigação das ideias prévias dos alunos}

Como falar de Arqueologia e de presença indígena em um contexto onde a formação histórica da cidade pode ser um importante entrave? O que os alunos pensam sobre a Arqueologia e a presença indígena? Eles estão realmente alheios a esta presença ou conseguem identificar o indígena na paisagem londrinense e relacioná-lo com o passado? E mais, conseguem reconhecer relações com os indígenas na sua história familiar?

Estes questionamentos levaram-me a definir os passos da ação arqueológica educativa: investigar e analisar as ideias prévias dos alunos em relação à temática arqueológica e indígena, consultando, igualmente, a disposição em aprender sobre estes assuntos. Em seguida, elaborar a proposta de intervenção, articulada com os documentos orientadores de Educação no Paraná e com o plano pedagógico da escola e avaliar os resultados. 
6 Entenda-se por conhecimento prévio o que o aluno já sabe (conceitos, símbolos, princípios, fatos, ideias, imagens) sobre determinada proposta de ensino (ALEGRO, 2008: 24).

7 O mesmo não ocorre quando há uma aprendizagem mecânica, concebida como aprendizagem de novas informações com pouca ou nenhuma associação a conceitos relevantes existentes na estrutura cognitiva (ALEGRO, 2008: 25). Neste tipo de aprendizagem, muito estimulada na escola, novas informações são memorizadas pelos alunos, sem nenhuma reflexão e interação com as informações de sua estrutura cognitiva (MOREIRA, 2000: 4).

8 A investigação em Educação Histórica tem se desenvolvido em vários países, como Inglaterra, Estados Unidos e Canadá. Outros seguem na mesma esteira, como Portugal, Espanha e Brasil (BARCA, 2001: 13 e GEVAERD, 2009: 34).
9 Os estudos qualitativos realizados na década de 1980, na Itália, por Antônio Calvani, a partir da análise das ideias dos alunos, de perguntas e de observação, mostram um resultado contrário. Em sua pesquisa empírica, Calvani demonstrou que crianças de 6 anos possuem um horizonte histórico infantil e chegam à escola primária com esquemas mentais que dotam certo "sentido" à História. Este autor assegura que estes alu-
No universo da Educação, a investigação sobre as ideias prévias dos alunos é uma tendência indicada pela Psicologia Cognitiva desde a década de 1960, por David Ausubel, quando deu início aos estudos sobre aprendizagem significativa. Este autor pontuava que somente pode-se aprender a partir daquilo que já se conhece, isto é, se o objetivo é promover uma aprendizagem significativa é preciso averiguar o conhecimento prévio ${ }^{6}$ e ensinar de acordo (AUSUBEL et al., 1980).

A aprendizagem significativa caracteriza-se pela interação entre o novo conhecimento e o conhecimento prévio. Neste processo de interação, o novo conhecimento adquire significados para o aprendiz e o conhecimento prévio fica mais rico, mais elaborado, em termos de significado, e adquire mais estabilidade7 (MOREIRA, 2000: 3).

Ademais, a aprendizagem significativa não está condicionada à idade, exceto em crianças recém-nascidas, nem à prontidão, mas ao conhecimento prévio de que o aluno dispõe, à predisposição para aprender significativamente, à potencialidade do material de aprendizagem e às estratégias metodológicas aplicadas pelo professor (ALEGRO, 2008: 32).

Transpondo a teoria da aprendizagem significativa, da segunda metade da década de 1960, para o ensino de História, Alegro (2008: 14) afirma que aquela é praticamente desconhecida no espaço para a pesquisa sobre ensino e aprendizagem desta disciplina no Brasil. O contrário ocorre nas áreas de Física, Biologia e Linguística, onde prosperam estudos nesta direção.

Por outro lado, têm ganhado força e se ampliado, desde a década de 1990, o campo da Educação Histórica (Cognição e Ensino de História) ${ }^{8}$, que se dedica a compreender como os alunos aprendem esta disciplina, incluindoos, de fato, como sujeitos no processo de construção do conhecimento, interessando-se pelas suas ideias (ALEGRO, 2008: 14).

Como pressuposto metodológico, os pesquisadores da Educação Histórica analisam as ideias que os sujeitos expressam em e acerca da História, através de exercícios concretos. Este campo de investigação afasta-se de critérios generalistas de categorização do pensamento em níveis abstratos e concretos, que foi estabelecido, na década de 1970, tendo por base as ciências exatas.

Estes critérios generalistas conduziram alguns autores a concluírem que a História era complexa para ser compreendida entre alunos com idades mentais inferiores a 16 anos. Tais conclusões ofereceram argumentos, nas décadas de 1970 e 1980, contra a inclusão da História no currículo escolar obrigatório, enquanto disciplina autônoma, substituindo-a por uma área integrada de Estudos Sociais (BARCA, 2001: 13 e TREPAT; COMES, 2008: 50).

Sob influência destes critérios, ainda hoje, no campo do ensino de História, há estudiosos convictos de que alguns temas são de difícil compreensão para os alunos, como por exemplo, a pré-história9 ${ }^{9}$. Todavia, pesquisas sistemáticas sobre o pensamento histórico dos alunos indicam que eles têm condições de aprender sobre qualquer temática, abordadas de inúmeras maneiras, e que é possível encarar a aprendizagem da História numa perspectiva qualitativa (BARCA, 2001: 14).

Sendo assim, na mesma direção da teoria da aprendizagem significativa, que pontua o conhecimento prévio como o fator isolado mais importante na determinação do processo de ensino (ALEGRO, 2008: 15), os estudos sobre 
nos manifestam uma capacidade clara para imaginar e conceber tempos mais recuados. Para o autor, as crianças de 6 anos já têm algumas ideias dos grupos pré-históricos (caçavam animais, viviam nas cavernas e vestiam peles). No entanto, também se observa a existência de contaminações, tais como "caçavam dragões" e "dinossauros", provavelmente influências advindas de desenhos. A partir de seus resultados, Calvani sugere que o trabalho com esta temática não seja ignorado nos anos iniciais e que parta das ideias que os alunos têm sobre este passado mais distante (TREPAT; COMES, 2008: 57-62).

10 A avaliação museológica é uma área ampla que compreende avaliar as ações do Museu, especialmente em três níveis de preocupação: o primeiro é com relação ao público, o segundo, às ações e atividades desenvolvidas e o terceiro, às condições de produção e de emissão (CURY, 2004: 93).

11 A investigação aqui citada foi desenvolvida com pouco mais de 50 alunos do quinto ano do ensino fundamental (a maioria deles com 10 anos de idade) da Escola Municipal Professor Leônidas Sobriño Porto. Esta ação foi realizada entre os meses de junho a novembro de 2011. A escola localiza-se em uma região marcada pela violência, cujo perfil socioeconômico da comunidade é caracterizado pela classe econômica baixa e média.

12 Esta etapa foi realizada a partir de três exercícios distintos: atividade com desenho, aplicação de questionário e conversa informal com os alunos. Este último exercício, por conta das normas da Secretaria Municipal de Educação, não foi gravado. Mesmo assim, foi possível registrar algumas informações dos alunos acerca da presença indígena. Esta etapa, que será apresentada integralmente na tese de doutorado da autora, contou com a colaboração de Ana Pinõn e Regina Célia Alegro.

13 Grande parte do grupo investigado conheceu o Museu Histórico Padre Carlos Weiss no ano anterior, pelas ações do projeto "Conhecer Londrina", desenvolvido pela Secretaria da Educação. Tal projeto consiste num roteiro de visitação aos considerados "pontos históricos mais expressivos", executado conforme o horário de estudo a Educação Histórica indicam que para que a História, em sala de aula, não seja uma regurgitação do passado, o professor deve estimular o pensamento crítico de seus estudantes, adotando alguns procedimentos específicos, como investigar as ideias que eles já possuem, possibilitando a reflexão sobre diferentes hipóteses e exercitando a seleção de diferentes respostas (BARCA, 1998 apud GEVAERD, 2009: 160).

Investigar o público também é uma tendência discutida pela Museologia que, embora seja uma área de pesquisa do Museu e não do contexto escolar, mantém importantes relações com a escola. Estudos na área de comunicação museológica apontam que o público é construtor ativo de sua própria experiência e o Museu (com a exposição e a ação educativa) é um local de encontro, negociação e atribuição de sentidos e significados da mensagem compartilhada (CURY, 2004: 91). Desse modo, o Museu precisa conhecer os seus inúmeros sujeitos e isto pode ocorrer a partir da pesquisa de recepção, sendo esta uma das possibilidades da avaliação museológica ${ }^{10}$.

Aplicar uma pesquisa de recepção é colocar-se à disposição para compreender quais os usos que o público faz do Museu e como este público, tão heterogêneo, atribui significados para o patrimônio ali existente (CURY, 2004: 94). Assim, os estudos de recepção tornam-se fundamentais para compreender os alcances, as interpretações geradas e os significados atribuídos pela comunicação museológica.

A partir da contribuição destas tendências, o caminho metodológico selecionado para a realização da ação arqueológica educativa ${ }^{11}$ foi composto pelas seguintes etapas:

- Coleta das ideias prévias dos alunos ${ }^{12}$ sobre a Arqueologia e a presença indígena na região;

- Descrição e análise quantitativa e qualitativa das ideias prévias;

- Articulação dos resultados com as políticas educacionais, tanto local quanto regional;

- Elaboração da intervenção pedagógica;

- Avaliação das ideias dos alunos posteriores à intervenção pedagógica.

Alguns apontamentos sobre as ideias prévias dos alunos em relação à temática arqueológica e indígena

A análise das ideias dos alunos em relação à temática arqueológica e indígena obedeceu aos métodos quantitativos e qualitativos, uma vez que ambos os métodos não são antagônicos ou excludentes, mas, ao contrário, podem ser complementares (TIRADO SEGURA, 2003: 29).

O método quantitativo foi utilizado para averiguar as seguintes questões: se o que mais marcou a experiência dos alunos em relação ao Museu está ligado ao patrimônio arqueológico indígena ${ }^{13}$, se eles conheciam a Arqueologia e, finalmente, se havia interesse em aprender sobre o assunto.

A investigação demonstrou que os 41 alunos que conheceram o Museu Histórico de Londrina indicaram como mais significativos os objetos e os monumentos ligados à colonização da cidade e aos pioneiros, especialmente aqueles caracterizados por sua monumentalidade, como o trem e a ferrovia ${ }^{14}$. Outros objetos com maior ocorrência foram as armas, apontadas pelos meninos, as fotos históricas e os brinquedos, pelas meninas. 
(HILDEBRANDO, 2010: 13). Esta visita inclui o Museu Histórico da cidade e o contato com os objetos relacionados ao patrimônio arqueológico indígena. Vale ressaltar que a exposição destes objetos é resultado da ação da professora Maria Cristina Bruno do MAE-USP, que assinou o projeto de revitalização desta instituição entre 1996 a 2000. O antigo acervo em exposição era composto por objetos pertencentes aos pioneiros da cidade, entregues ao Museu por meio de doações. O acervo arqueológico indígena é constituído por instrumentos e fragmentos de pedra lascada e polida, peças de cerâmica, tais como vasilhas e uma urna funerária.

14 Desde 1986, o Museu Histórico ocupa o prédio da antiga Estação Ferroviária de Londrina, inaugurada na década de 1950.

15 Deste grupo, apenas 1 aluno indicou diretamente a "urna funerária". O restante respondeu que o que mais gostou foi "dos objetos de índios".

16 Embora este artigo não tenha como objetivo discutir a questão da musealização do patrimônio arqueológico indígena pertencente ao Museu Histórico de Londrina destaca-se a importância de desenvolver estudos de recepção nesta instituição museal, pois a forma de exposição do acervo pode ter influenciado as respostas dos alunos.

17 Os 2 alunos restantes indicaram a escola e o museu. O que surpreende neste resultado é apenas 1 indicação do conhecimento de Arqueologia pelas informações escolares, já que na semana anterior ao teste, o conteúdo sobre a temática indígena havia sido tratado com o público. Neste conteúdo havia referências sobre o trabalho do arqueólogo e a Arqueologia.

18 Apesar de a imagem apresentar um pesquisador do sexo masculino, durante as atividades realizadas com os alunos, tomou-se o cuidado de informar que esta é uma profissão realizada igualmente por mulheres.

19 A análise de conteúdo é um conjunto de técnicas utilizadas no contexto da análise de discurso (MORAES, 1999; 2003 e ROCHA DEUSDARÁ, 2005 etc.) que valoriza o rigor metodológico e possibilita um maior aproveitamento que o objeto analisado possa conter. Sua proposta está na atribuição de sentido dos discursos apreendidos. Este recurso tem sido utilizado em trabalhos de Educação, Comunicação, Educação Ambiental etc.
A indicação de peças indígenas teve baixa ocorrência ( 3 alunos ${ }^{15}$ ), o que pode sugerir que o patrimônio arqueológico, o primeiro a ser contemplado na exposição, não chama atenção, talvez por estar em parte fragmentado e em menor quantidade. A própria localização na exposição pode ser um elemento que contribui para isto: as peças encontram-se numa pequena antessala, cuja passagem dá acesso a três galerias dedicadas, especialmente, aos "pioneiros", responsáveis pela fundação da cidade. Isto significa que há grande desvantagem em termos expositivos, pois os objetos indígenas são poucos, comparando-os aos objetos relacionados aos colonizadores ${ }^{16}$.

Entre aqueles que não tiveram a oportunidade de conhecer o Museu (10 alunos), suas expectativas resumem-se em encontrar "coisas boas e legais" e "coisas antigas". Tais indicações genéricas não permitem avaliar se "as coisas boas, legais e antigas" são objetos indígenas. Todavia, neste grupo houve também a indicação específica de objetos de arte e ossos de dinossauro, o que não equivale ao conteúdo expositivo do Museu citado. Isto sugere que as crianças possuem ideias sobre outros museus e esperam encontrar nesta instituição objetos correspondentes às suas ideias.

Sobre a Arqueologia, 37 alunos nunca haviam ouvido falar, apesar de este assunto ter sido tema em sala de aula. Para aqueles que afirmaram positivamente (14 alunos), quando foram questionados "onde", o que predominou foi a ausência de resposta (8 alunos). No entanto, os que responderam, apontaram como fonte de informação principal a TV (4 alunos $)^{17}$. Este dado pode sugerir o acesso a novelas, filmes e documentários que tratam a pesquisa arqueológica e temas correlatos.

Ainda sobre esta temática, os alunos foram convidados, a partir de uma imagem da prática arqueológica de escavação, a indicar quais objetos o arqueólogo ${ }^{18}$ procurava. Tanto os alunos que afirmaram conhecer Arqueologia quanto os que não conheciam apontaram, em sua maioria, "ossos de dinossauros", o que leva a crer que, independentemente do conhecimento sobre Arqueologia, os alunos apresentam ideias prévias do trabalho arqueológico, relacionando-o, sobretudo, ao passado distante, de coisas extintas.

Ademais, foi possível identificar que o público investigado tem curiosidade sobre o assunto e manifestou interesse em aprender sobre temas diferentes e de formas variadas. A pré-disposição em aprender existe. Nos casos em que não há esta pré-disposição, o argumento utilizado aponta o desconhecimento, ou seja, os alunos que não se interessavam em conhecer a Arqueologia argumentaram que era porque eles não sabiam exatamente o que era.

O método qualitativo, conforme discussões da análise de conteúdo ${ }^{19}$, foi usado para identificar dados sobre a temática indígena. Para tal análise, duas questões foram levadas em consideração. A primeira, os alunos tiveram como conteúdo escolar a temática indígena pouco antes da realização dos exercícios. O conteúdo estudado, sobre a História do Paraná, indicava a presença de indígenas muito antes, durante e depois da colonização. A segunda, o fato comum da circulação de índios na cidade, pois os Kaingang, da reserva do Apucaraninha, vendem objetos artesanais ou circulam como pedintes por toda a região, inclusive no bairro onde se localiza a escola. 
Para a análise qualitativa, a metodologia proposta compreendeu três procedimentos básicos:

- Desmontagem dos textos (no caso, os questionários e os desenhos);

- Estabelecimento de relações (criação de categorias)

- Captação do novo (análise das categorias).

Para começar a desmontagem dos instrumentos em questão, a pergunta de corte estabelecida foi "Como as crianças representam os índios no tempo (passado e presente) e na paisagem da região?". Desta pergunta de corte, surgiram 6 tipos de respostas diferentes, que foram agrupadas, as chamadas unidades de análise. A saber:

Alunos que acreditam que havia índios na região no passado

Alunos que não sabem se havia índios na região no passado

Alunos que acreditam que não havia índios na região no passado

Alunos que acreditam que há índios vivendo na região no presente

Alunos que não sabem se há índios vivendo na região no presente

20 Com as unidades de análise identificadas nas duas turmas, foram criadas categorias, de acordo com as respostas dos alunos, no intuito de compreender a pergunta de corte estabelecida. Esta categorização será apresentada integralmente na tese de doutoramento da autora.

21 As características comportamentais e as práticas de subsistência são elementos conectados e que compõem os aspectos culturais dos indígenas. Todavia, para melhor visualização das ideias prévias, eles serão citados distintamente.
Alunos que acreditam que não há índios vivendo na região no presente

Sendo assim, apresento alguns pontos elencados durante esta etapa, que contribuíram para a categorização das ideias prévias dos alunos ${ }^{20}$.

\section{Alunos que acreditam que havia índios na região no passado (27 alunos)}

- Grupo a que correspondeu à metade do público. Mesmo afirmando que havia índios na região no passado, 6 alunos indicaram que os primeiros a chegar ali foram os ingleses;

- Ao descrever o índio do passado, este grupo preocupou-se mais em citar aspectos comportamentais ${ }^{21}$ (andam nus, pintam os corpos) do que descrever práticas de subsistência (caça, pesca, coleta);

- Interessante destacar que esta unidade de análise também se preocupou em atribuir qualificações aos indígenas, bem como estabelecer comparações com a sociedade atual: "os índios do passado são parecidos com a gente", "são modernos", "falam a nossa língua"; "são alegres", "legais", "trabalhadores" etc. Acrescenta-se ainda que tal iniciativa pode estar associada com a dificuldade em imaginar uma alteridade tão distante no passado;

- Muito embora este grupo tenha pontuado a certeza da presença indígena, ao serem convidados a desenhar a floresta antes da construção da cidade de Londrina, indicando quem vivia e o que tinha lá, 11 alunos não desenharam os indígenas;

- O restante, que desenhou o indígena, optou por representá-lo mais pelas suas práticas de subsistência. 
- Grupo a que correspondeu pouco menos da outra metade do público. Este fato sugere que, mesmo com as informações escolares, os alunos não tinham certeza da presença de índios no passado da região;

- Embora não tenha a certeza desta presença, 16 alunos indicaram os indígenas como os primeiros habitantes do norte do Paraná;

- Para descrever os indígenas do passado, em sua maioria, citaram mais os aspectos comportamentais (andam nus, pintam os corpos) ou indicaram não saber responder;

- Apesar de incertos sobre esta presença, ao serem convidados a desenhar a floresta antes da construção da cidade, 10 alunos desenharam os indígenas, dando destaque para suas práticas de subsistência.

\section{Alunos que acreditam que não havia índios na região no passado (5 alunos)}

- Para 3 alunos, os ingleses foram os primeiros habitantes da região;

- O restante indicou os indígenas como primeiros habitantes da região;

- Deste grupo, 2 alunos atribuíram qualificações aos indígenas ("bons, legais, divertidos"), 2 disseram não saber descrevê-los e 1 citou aspectos comportamentais (andam nus, pintam os corpos);

- Os 2 alunos que apontaram os indígenas como primeiros habitantes da região, na atividade do desenho representaram o índio e suas práticas de subsistência.

\section{Alunos que acreditam que há índios vivendo na região no presente (27 alunos)}

- Grupo a que correspondeu à metade do público. Deste grupo, 15 alunos afirmaram ter visto um indígena pela cidade;

- Os alunos que viram um indígena no presente, optaram por descrevê-lo mais por suas características físicas (o tom de pele moreno teve destaque);

- Aqueles que não viram, optaram em descrever os indígenas do presente mais por aspectos comportamentais (andam nus, pintam os corpos);

- 3 alunos indicaram não saber descrever os indígenas do presente;

- Para a grande maioria desta unidade de análise, os indígenas de tempos atuais habitam a floresta;

- Dos 27 alunos que afirmaram que havia índios no presente, 14 já haviam afirmado esta certeza no passado, fato que pode sugerir tanto uma percepção de continuidade histórica quanto uma confusão entre o que é passado e o que é presente;

- Outros 11 alunos não têm certeza no passado, mas têm a certeza de que há índios na região no presente;

- Por fim, para 2 alunos não havia na região índios no passado, somente há no presente.

\section{Alunos que não sabem se há índios vivendo na região no presente (21 alunos)}

- Deste grupo, 11 alunos afirmaram já ter visto um índio, especialmente circulando pela cidade. Embora tenham visto, eles não têm certeza se há índios na região no presente; 
- 10 alunos afirmaram que não sabiam ou não se lembravam de como é o índio do presente, embora 4 deles já tenha visto um indígena;

- O restante, que descreveu o indígena, optou por citar suas características físicas, onde o tom de pele foi predominante (moreno); e comportamentais (andam nus, pintam os corpos);

- 13 alunos não conseguiram indicar onde os índios do presente vivem;

- Outros 7 alunos indicaram a floresta;

- Do total de 21 alunos, 13 têm a certeza da presença indígena no passado, mas não no presente;

- Outros 7 não sabem nem no passado e nem no presente;

- Por fim, 1 aluno acredita que não havia índios no passado e no presente ele não tem certeza.

\section{Alunos que acreditam que não há índios vivendo na região no presente ( 3 alunos)}

- Para 2 alunos deste grupo não havia índios na região no passado e não há no presente;

- 1 aluno não sabe no passado, mas tem certeza de que não há índios na região no presente;

- Nenhum aluno deste grupo indicou ter visto um indígena;

- Deste grupo 1 aluno descreveu o indígena do presente, indicando seus aspectos físicos:

- Para esta unidade de análise, os índios vivem na floresta ou em um lugar distante.

\section{Considerações finais}

Antes de algumas considerações sobre as ideias prévias do público investigado, é importante salientar um esforço recente em entender o que os alunos pensam sobre os índios, que pode ser encontrado na publicação "A Temática Indígena na Escola: subsídios para professores", 2011, de Pedro Paulo Abreu Funari e Ana Piñon. Na obra, que se preocupou em oferecer elementos para os professores discutirem a temática indígena na sala de aula, os autores apresentaram os resultados de uma ampla pesquisa realizada em escolas do Rio de Janeiro, Niterói, Campinas e Natal, com alunos dos sextos aos nonos anos, com o objetivo de identificar como este público percebe os indígenas.

Os resultados mostraram avanços e limites das políticas educacionais nos últimos anos. O principal aspecto positivo foi a identificação dos índios como parentes. Este reconhecimento é um avanço considerável, uma vez que, por muitos séculos, qualquer parentesco com os índios era considerado vergonhoso. Todavia, uma limitação evidente foi o fato da maioria dos alunos afirmarem que os indígenas estão no Brasil há quinhentos anos, o que sugere o desconhecimento sobre o processo de ocupação humana no território nacional e a desconsideração sobre a colonização européia como processo de expropriação (FUNARI; PIÑON, 2011: 109-112).

No caso da investigação aqui proposta, em conversa informal com os alunos, estes não se sentiram à vontade em afirmar algum parentesco indígena e tiveram imensas dificuldades em responder quando perguntados sobre o 
tempo em que os índios habitam as terras brasileiras. Para a maioria deles, menos de 500 anos.

A partir da análise das ideias prévias, pude elencar outras considerações: o passado para as crianças é constituído de informações fragmentadas; na estrutura cognitiva da criança, o índio existe como um ser exótico e estereotipado do passado e que, para a maioria, ainda mantém as mesmas características culturais no presente, muito embora eles se sintam mais à vontade em descrever o indígena do passado.

Apesar de a maioria dos alunos ter a informação escolar que os indígenas foram os primeiros habitantes da região, apenas pouco mais da metade deles conseguiu associá-los à paisagem local na atividade do desenho.

Outra questão foi o fato de que tanto o indígena quanto a paisagem local foram confundidos com o negro, a temática africana e a afro-brasileira. Alguns alunos descreveram os índios do passado e do presente como "negros". Além disso, animais africanos foram utilizados como elementos compositivos de muitos desenhos que representavam a paisagem anterior à colonização.

Diante destas considerações, mostram-se bastante importantes ações arqueológicas desenvolvidas no contexto escolar. A proposta não é impor novas versões históricas aos alunos. Ao contrário, o que se pretende é, pela perspectiva do conhecimento arqueológico, apresentar-lhes novos elementos para que, de maneira autônoma, possam confrontar as novas ideias com as já existentes.

Agradecimentos Ao professor Pedro Paulo Abreu Funari, ao Laboratório de Arqueologia Pública, em especial, à professora Aline Vieira de Carvalho.

\section{Bibliografia}

ALEGRO, Regina Célia. Conhecimento prévio e aprendizagem significativa de conceitos históricos no Ensino Médio. Tese (Doutorado em Educação), Universidade Estadual Júlio de Mesquita Filho, UNESP, Marília, São Paulo, 2008.

AUSUBEL, David P.; NOVAK, Joseph D.; HANESIAN, Helen. Psicologia Educacional. Trad. De Eva Nick e outros. Rio de Janeiro: Interamericana, 1980.

BARCA, Isabel. Educação Histórica: uma nova área de investigação. Revista da Faculdade de Letras HISTÓRIA, Porto, III Série, vol. 2, p. 13-21, 2001.

CHAGAS, Mario. Diabruras do Saci: museu, memória, educação e patrimônio. IPHAN - Musas Revista Brasileira de Museus e Museologia. Brasília: IPHAN, n. 1, 2004. p. 136146.

CARNEIRO, Carla Gibertoni. Ações Educativas no contexto da Arqueologia Preventiva: uma proposta para a Amazônia. Tese (Doutorado em Arqueologia), Museu de Arqueologia e Etnologia, Universidade de São Paulo, São Paulo, 2009.

CURY, Marília Xavier. Os usos que o público faz dos Museus - A (re) significação da cultura material e do Museu. Musas (IPHAN), MinC:IPHAN:DEMU, n. 1, 2004. p. 86106.

FUNARI, Pedro Paulo Abreu; PIÑON, Ana. A temática indígena na escola: subsídios para professores. São Paulo: Contexto, 2011. 
FUNARI, Pedro Paulo Abreu; ROBRAHN-GONZÁLEZ, Erika Marion. Editorial. Revista de Arqueologia Pública. São Paulo, n.3, 2008. p. 3.

GEVAERD, Rosi T. A narrativa histórica como uma maneira de ensinar e aprender História: o caso da História do Paraná. Tese (Doutorado em Educação), Universidade Federal do Paraná, Curitiba, 2009.

HILDEBRANDO, Gilberto. O Museu e a Escola: memórias e histórias em uma cidade de formação recente - Londrina/PR. Dissertação (Mestrado em História), Universidade Estadual de Londrina, Londrina, 2010.

LIMA, Leilane Patrícia; ZARPELÃO, Sandro Heleno Morais. O café em Londrina e no Paraná: abordagens para a exploração do tema em sala de aula. In: ALEGRO, Regina Célia et al. Temas e questões para o ensino de história do Paraná. Londrina: EDUEL, 2008. p. 197-238.

MAGALHÃES, Leandro Henrique; ZANON, Elisa Roberta; CASTELO BRANCO, Patrícia. M. Educação Patrimonial: da teoria à prática. Londrina: Editora Unifil, 2009.

MORAES, Roque. Uma tempestade de luz: a compreensão possibilitada pela análise textual discursiva. Ciência e Educação, v. 9, n. 2, 2003. p. 191-211.

MORAES, Roque. Análise de Conteúdo. Revista Educação, Porto Alegre, v. 22, n. 37, 1999. p. 7-32.

MOREIRA, Marco Antônio. Aprendizagem Significativa Subversiva. Atas do III Encontro Internacional sobre Aprendizagem Significativa, Lisboa (Peniche), 2000. p. 33-45. (versão revisada e estendida disponível no site http://moreira.if.ufrgs.br/ apsigcritport.pdf) Acesso em: 09/02/2012.

MOTA, Lúcio Tadeu. As Guerras dos índios Kaingang - a história épica dos índios Kaingang no Paraná (1769 - 1924). 2ª ed. rev. e ampl. Maringá: EDUEM, 2009.

História do Paraná: ocupação humana e relações interculturais. Maringá:

EDUEM, 2005.

NOELLI, Francisco Silva. A ocupação humana na região Sul do Brasil: Arqueologia, debates e perspectivas (1872-2000). Revista USP, São Paulo, número 44, 1999-2000. p. 218-269.

PARELLADA, Cláudia Inês. Estudo arqueológico no alto vale do rio Ribeira: área do gasoduto Bolívia-Brasil, Trecho X, Paraná. Tese (Doutorado em Arqueologia), Museu de Arqueologia e Etnologia, Universidade de São Paulo, São Paulo, 2005.

RAMOS, Igor Guedes; ALVES, Samira Ignácio. Índios: um silêncio ao norte do Paraná. ALEGRO, Regina Célia et al. Temas e questões para o ensino de História do Paraná. Londrina: EDUEL, 2008. p. 175-196.

RIBEIRO, Pedro Augusto Mentz. Os mais antigos caçadores-coletores do Sul do Brasil. TENÓRIO, M. C. (Org.). Pré-História da Terra Brasilis. Rio de Janeiro: UFRJ, 2000. p. 7588.

ROCHA, Décio; DEUSDARÁ, Bruno. Análise de Conteúdo e Análise do Discurso: aproximações e afastamentos na (re) construção de uma trajetória. ALEA, vol. 7, n. 2, 2005. p. 305-322. 
SILVEIRA, Flávio Leonel Abreu da; BEZERRA, Márcia. Educação Patrimonial: perspectivas e dilemas. ECKERT, C.; LIMA FILHO, M. F. BELTRÃO, J. (Orgs.). Antropologia e Patrimônio Cultural: diálogos e desafios contemporâneos. Florianópolis: Nova Letra: ABA: Fundação Ford, 2007. p. 11-21.

TIRADO SEGURA, Felipe. Contribuciones de la evaluación al desarrollo de la museología. Encontro de profissionais de Museus. A comunicação em questão: exposição e educação, propostas e compromissos. São Paulo; Brasília: MAE, USP: STJ, 2003. p. 19-42.

TREPAT, Cristòfol; COMES, Pilar. El tiempo y el espacio en la didáctica de las ciencias sociales. Barcelona: Editorial: GRAÓ, 2008.

WACHOWICZ, Ruy. História do Paraná. 9a edição. Curitiba: Imprensa Oficial do Estado, 2001. 